\title{
Evidence for CSF-vascular compliance coupling in normal pressure hydrocephalus
}

\author{
Stephen Dombrowski ${ }^{1}$, Kevin Crutchfield ${ }^{2}$, Karolyn Ligon ${ }^{1}$, Judith Becker ${ }^{1}$ \\ and Mark Luciano*1
}

\author{
Address: ${ }^{1}$ Department of Neurosurgery, Section of Pediatric and Congenital Neurosurgery, The Cleveland Clinic, 9500 Euclid Avenue, Cleveland, \\ OH 4195, USA and 2New Jersey Neuroscience Institute, JFK Medical Center, 65 James Street, Edison, New Jersey 08818, USA \\ Email: Mark Luciano* - lucianm@ccf.org \\ * Corresponding author
}

from 52nd Annual Meeting of the Society for Research into Hydrocephalus and Spina Bifida

Providence, RI, USA. II-I4 June 2008

Published: 3 February 2009

Cerebrospinal Fluid Research 2009, 6(SuppI I):S36 doi:I0.II86/I743-8454-6-SI-S36

This abstract is available from: http://www.cerebrospinalfluidresearch.com/content/6/SI/S36

(C) 2009 Dombrowski et al; licensee BioMed Central Ltd.

\section{Background}

The underlying pathophysiology in Normal Pressure Hydrocephalus (NPH) most likely involves changes in brain parenchyma, vascular resistance, and CSF circulation resulting in decreased intracranial compliance and diminished cerebral blood flow (CBF). Changes in blood vessel reactivity may play an important role in the pathophysiology and diagnosis of NPH. As a result, it has been suggested that Transcranial Doppler (TCD), a non-invasive assessment of blood flow velocity in major intracranial arteries, may be useful in distinguishing specific blood vessel segments and reactivity patterns unique to $\mathrm{NPH}$. The present study is a prospective, clinical trial of 30 patients undergoing extended CSF trial lumbar drainage for the diagnosis of NPH using standard TCD monitoring and newly developed Hemodynamic Vascular Analysis (HVA, New Health Sciences, Inc., and K.C.).

\section{Materials and methods}

In thirty patients between 53-90 y.o. (mean 72.2) who presented with ventriculomegaly and one or more of the triad symptoms (gait impairment, cognitive impairment, and urinary incontinence), TCD measures were obtained immediately before and after 36-hour, lumbar CSF drainage procedure for the diagnosis of NPH. TCD parameters (MFV, PSV, SA, and PI) as well as data converted to HVA through algorithmic calculations and fast Fourier transform were obtained from 23 vessel segments and/or ensembles of segments in 16 CSF drainage "responders" and 14 "non-responders." HVA parameters of flow dynamics included Hemodynamic Flow Index (MFV/PI), Hemodynamic Pressure Index (lnSA/PI), and Hemodynamic Compliance Index (lnSA/MFV). TCD-HVA values at presentation and percent change with CSF trial drainage for responders and non-responders were reported.

\section{Results}

Overall, we found significant differences between responders and non-responders for MFV and PSV at presentation ( $p \leq 0.01)$ and after CSF removal ( $p \leq 0.05)$. We also found that extended CSF drainage resulted in a change in pulsatility (PI) with functional response. These findings were further confirmed by HVA which showed a unique pattern of specific vessel sites (4 parameters) that was significantly different between responders and nonresponders in combination and individually $(\mathrm{p}<0.017)$; specifically decreased flow velocities in middle cerebral and vertebral arteries, and diminished compliance in the anterior cerebral artery were reported. This discriminate function was applied to the specific cohort and was able to classify treatment responders from non-responders with $81.8 \%$ sensitivity and $75 \%$ specificity.

\section{Conclusion}

Our findings showing a change in pulsatility (PI) associated with CSF drainage indicate the influence of the CSF 
space on vessel reactivity. Further, the association between pulsatility and CNS function suggests that this influence may be clinically significant. The differences in mean and peak velocity at presentation and after CSF removal may reflect underlying deficits and recovery of blood flow. Although the initial identification of specific vessels and patterns associated with CSF trial response using TCDHVA may be unique to NPH, these preliminary findings are not physiologically intuitive and must be validated in a prospective study in a new patient set.

Support for this investigation provided by New Health Sciences, Inc.

Publish with Bio Med Central and every scientist can read your work free of charge

"BioMed Central will be the most significant development for disseminating the results of biomedical research in our lifetime. " Sir Paul Nurse, Cancer Research UK

Your research papers will be:

- available free of charge to the entire biomedical community

- peer reviewed and published immediately upon acceptance

- cited in PubMed and archived on PubMed Central

- yours - you keep the copyright

Submit your manuscript here:

http://www.biomedcentral.com/info/publishing_adv.asp 